\title{
High Quality Hydrothermal ZnO Crystals
}

M. Suscavage, M. Harris, D. Bliss, P. Yip, S.-Q. Wang, D. Schwall, L. Bouthillette, J. Bailey,* M. Callahan,* D. C. Look,** D. C. Reynolds, ** R. L. Jones,*** and C. W. Litton***

Air Force Research Laboratory, Sensors Directorate, Hanscom AFB, MA 01731, U.S.A. *Solid State Scientific Corporation, Hollis, NH 03049, U.S.A.

**University Research Center, Wright State University, Dayton OH 45435, U.S.A. ***Air Force Research Laboratory, Materials and Manufacturing Directorate, Wright-Patterson AFB, OH 45433, U.S.A.

\section{MRS Internet J. Nitride Semicond. Res. 4S1, G3.40(1999)}

\begin{abstract}
Zinc Oxide crystals have historically been grown in hydrothermal autoclaves with a basic mineralizer; however, doubts have been raised about the quality of such crystals because they have often exhibited large x-ray rocking curve widths and low photoluminescence (PL) yield with large linewidths. Several $\mathrm{ZnO}$ crystals were grown hydrothermally and sliced parallel to the c-plane. This resulted in opposite surfaces (the $\mathrm{C}^{+}$and $\mathrm{C}^{-}$) exhibiting pronounced chemical and mechanical differences. Different surface treatments were investigated and compared by PL both at room temperature and liquid helium temperatures, and by double axis X-ray rocking curve measurements. The high quality of hydrothermally-grown $\mathrm{ZnO}$ is substantiated by the narrow rocking curve widths and sharp PL peaks obtained. A critical factor in obtaining these results was found to be surface preparation.
\end{abstract}

\section{INTRODUCTION}

Zinc oxide is a wide band-gap semiconductor $(3.37 \mathrm{eV})^{1}$ with potential for applications as emitter devices in the blue to ultraviolet region and as a substrate material for $\mathrm{GaN}$ based devices. Because of its high vapor pressure, growth of $\mathrm{ZnO}$ from the melt is difficult, and growth by vapor deposition is difficult to control. Hydrothermally grown $\mathrm{ZnO}$ has been used previously ${ }^{2}$ for surface acoustic wave devices, which do not need the high quality surface that optical or semiconductor device applications require. Therefore, we have performed an initial study of surface preparation and subsequent characterization on hydrothermally grown $\mathrm{ZnO}$ in order to produce surfaces suitable for epitaxy.

\section{EXPERIMENTAL}

Hydrothermal autoclaves made of high strength steel were used for crystal growth. Because of the high normality of the mineralizing solution, a sealed platinum liner (see reference 2 for an example) was used to isolate the crystal growth environment from the walls of the autoclave. ${ }^{2}$ The mineralizer solution was a mixture of $\mathrm{Li}_{2} \mathrm{CO}_{3}, 4 \mathrm{~N} \mathrm{KOH}$, and $4 \mathrm{~N} \mathrm{NaOH}$, with the fill quantity at $80 \%$. The nutrient was prepared from $99.99 \% \mathrm{ZnO}$ (Alfa Aesar) powder having particle size $<3 \mu \mathrm{m}$, which was sintered for $4 \mathrm{hrs}$ in air at $1350^{\circ} \mathrm{C}$ in a platinum crucible. The seeds were (0001) plates of $\mathrm{ZnO}$ from previous hydrothermal growth runs. During growth, the nutrient zone was at $355^{\circ} \mathrm{C}$ with a temperature gradient of $10^{\circ} \mathrm{C}$ declining towards the seed zone. Growth rates in the [0001] directions on the basal seed plates averaged 10 mils per day for the 30 
day runs, but growth was anisotropic: the ratio of growth rates between the fast $\left(\mathrm{C}^{+}\right)$and slow $\left(\mathrm{C}^{-}\right)$growth directions was 3 to 1 .

Wafers were sliced and the $\mathrm{C}^{+}$and $\mathrm{C}^{-}$planes were identified by etching in nitric acid, following the method developed by Mariano and Hanneman. ${ }^{3}$ Surface properties were analyzed by : double axis $\mathrm{x}$-ray rocking curve with a high resolution four circle $\mathrm{x}$-ray diffractometer; room temperature PL with a $0.25 \mathrm{~m}$ grating monochrometer, ccd detector, and a $275 \mathrm{~nm}, 5 \mathrm{~ns}$ pulsed variable wavelength laser source; PL at $4 \mathrm{~K}$ with a $1.26 \mathrm{~m}$ grating spectrometer and at $2.1 \mathrm{~K}$ with a high resolution $4.0 \mathrm{~m}$ grating spectrometer, both equipped with an RCA C31034A photomultiplier and employing a HeCd laser.

For this study, two different surface conditions or surface treatments were studied: a mechanical polish provided by a commercial service, and a chemomechanical polish performed by Eagle-Picher Corporation. We also compared our hydrothermal $\mathrm{ZnO}$ (grown at AFRL/Hanscom) to vapor-phase grown $\mathrm{ZnO}$ provided by Eagle-Picher. For this comparison, low temperature PL was used to evaluate the presence or absence of excitonic peaks.

\section{RESULTS AND DISCUSSION}

The crystal growth characteristics of hydrothermal $\mathrm{ZnO}$ are dictated by anisotropy between the two opposite surfaces of the basal plane. The opposite sides of a basal plane wafer have different atomic arrangements at their surfaces due to this anisotropy. That is, the $\mathrm{C}^{+}$side comprises a $\mathrm{Zn}$-rich layer, and the $\mathrm{C}^{-}$side comprises an O-rich layer. The resulting electronic charge distribution is illustrated in Fig. 1, adapted from the work of Mariano and Hanneman. ${ }^{3}$

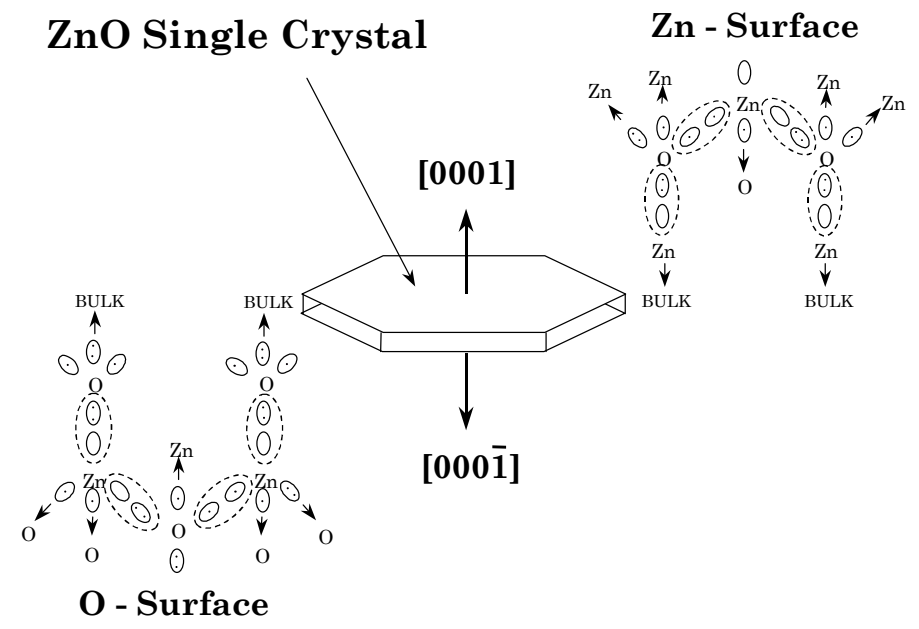

Figure 1. Electronic Charge Distribution of Zinc Oxide.

Typically, seeds were slices cut parallel to the basal plane to maximize the yield of (0001) wafers. The growth habit of hydrothermal $\mathrm{ZnO}$ crystals grown on basal plane seeds is shown in Fig. 2. ${ }^{4}$ For crystal growth in the [0001] direction or $\mathrm{C}^{+}$sector, the growth rate was faster and the crystal color is clear to light yellow-green. For the [0001] direction or $\mathrm{C}^{-}$sector, the growth rate was about $1 / 3$ as fast and the color is typically dark green. Slices were cut as shown from the light green and dark green sectors to distinguish between their chemical and electronic properties. Because of the different growth rates, we speculate that the different colors are due to a difference in impurity incorporation between the two sectors. 


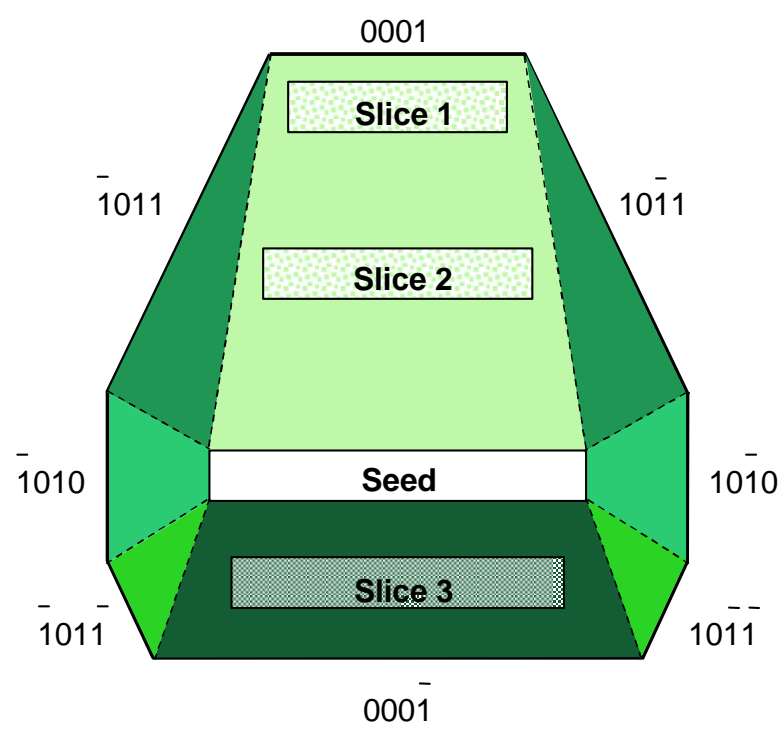

Figure 2. Growth habit of hydrothermal Zinc Oxide.

Trace analysis by glow discharge mass spectrometry (GDMS) revealed a slight difference in impurity concentration between the two sectors. The dark sector contains 3-5 ppm of iron, about twice as much as the light sector. This result is similar to other reports on $\mathrm{ZnO} .{ }^{4}$ The light sector contains 5-6 ppm each of aluminum and silicon, twice as much as the dark sector. Analysis of the free electron concentration by temperature dependent Hall effect revealed further differences. The dark green sector had a low resistivity, with a free carrier concentration of $3 \times 10^{18} \mathrm{~cm}^{-3}$ at room temperature. The light green sector showed high resistivity, with room temperature electron concentration of $2 \times 10^{12} \mathrm{~cm}^{-3}$ and mobility of $\sim 175 \mathrm{~cm}^{2} / \mathrm{V}-\mathrm{sec}$. From a fit of $\mathrm{n} v \mathrm{vs} .1 / \mathrm{T}$, it was determined that the dominant donor in this sector is $0.34 \mathrm{eV}$ below the conduction band, and that donor and acceptor concentrations were about $7 \times 10^{15}$ and $1 \times 10^{15} \mathrm{~cm}^{-3}$, respectively. Thus, the purity in this sector is quite high.

One possible explanation accounting for the chemical and electrical data could entail growth-rate dependent incorporation of impurities or native defects. Differential segregation of impurities may contribute to the chemical and electronic differences between the two sectors, but there is no evidence that dopants like silicon or aluminum could be responsible for the deep level defect. Nor is there any evidence that iron could account for the shallow donor in the dark sector. Another possible explanation is that stoichiometric defects, complexed with impurities, act as compensation centers in the light sector, reducing the free-carrier optical absorption.

Each slice cut parallel to the C-plane has both a Zn-side and an O-side. Both sides of the wafers were polished in the same manner to determine the mechanical and optical properties of the two surfaces. The two surfaces have different chemical reactivities and mechanical properties as a result of surface anisotropy, so that given the same surface treatment, each side shows different results. This is illustrated in Table I which shows the rocking curve half-widths and PL intensities for two different polishing methods. The x-ray rocking curve measures strain in the sub-surface region, where $\mathrm{Cu} \mathrm{K} \alpha$ radiation at $1.54 \AA$ has a penetration depth of about 2 microns. A dramatic reduction by a factor of two is seen in the rocking curve width after the combined chemical-mechanical polish. A similar result is seen in the PL intensity at room temperature. At the excitation wavelength of $275 \mathrm{~nm}$ the absorption coefficient of $\mathrm{ZnO}$ is very high, and therefore the probe depth is on the order of a few nanometers. Thus PL is a very good indicator of surface quality. A comparison of PL intensities indicates the surface is much less damaged by chemical polishing than by mechanical polishing. 
Table I. Effect of different surface treatments on hydrothermal $\mathrm{ZnO}$

\begin{tabular}{|l|c|c|c|c|}
\hline \multicolumn{1}{|c|}{$\begin{array}{c}\text { Surface Preparation } \\
\text { Description }\end{array}$} & \multicolumn{2}{c|}{ Mechanical polish } & \multicolumn{2}{c|}{ Eagle Picher polish } \\
\hline Crystal faces & $\mathrm{C}^{+}$ & $\mathrm{C}^{-}$ & $\mathrm{C}^{+}$ & $\mathrm{C}^{-}$ \\
\hline $\begin{array}{l}\text { X-ray rocking curve } \\
\text { FWHM (arc-sec) }\end{array}$ & 108 & 104 & 43 & 37 \\
\hline $\begin{array}{l}\mathbf{3 . 2 8} \text { eV PL relative } \\
\text { intensity at room temp }\end{array}$ & 0.04 & 0.5 & 1.1 & 1.5 \\
\hline
\end{tabular}

Photoluminescence measurements at room temperature are useful for comparing the quality of $\mathrm{ZnO}$ samples. Because of the large exciton binding energy of $60 \mathrm{meV}$, exitonic emission will survive well above room temperature. ${ }^{1}$ Thus, the measurement is an indicator for possible stimulated emission and lasing from $\mathrm{ZnO}$ at room temperature. Under pulsed excitation at 275 $\mathrm{nm}$, the emission peak position is close to the expected energy of the free exciton. The bandgap of $\mathrm{ZnO}$ at room temperature is $3.37 \mathrm{eV},{ }^{1}$ and the observed PL emission peak is at $3.28 \mathrm{eV}$. A comparison of the PL emission spectra for the same $\mathrm{ZnO}$ wafer after the two different surface treatments is shown in Figure 3.

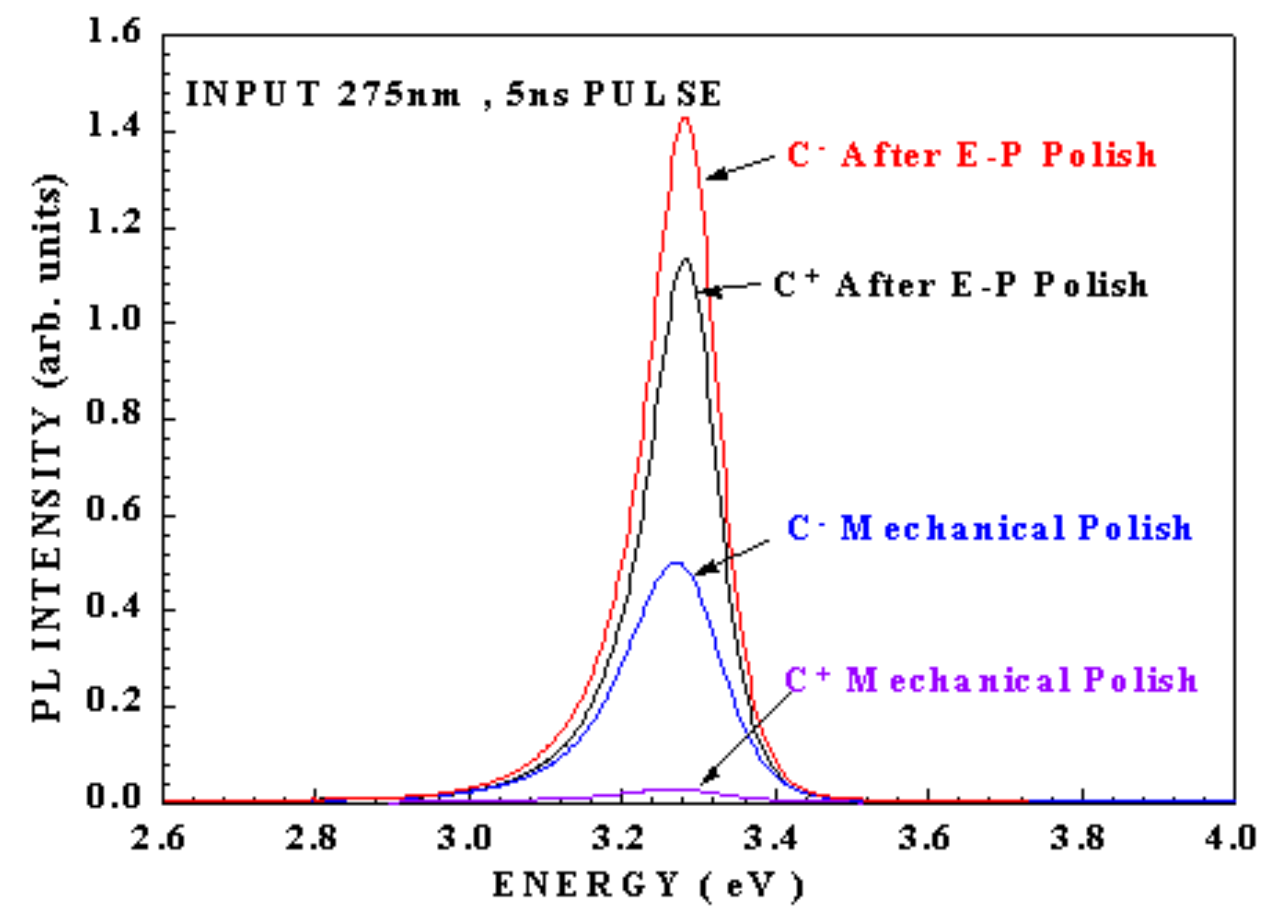

Figure 3. Room Temperature PL comparing different polishes.

Low temperature PL measurements give additional information on the fine structure of the emission. Photoluminescence (at $2.1 \mathrm{~K}$ ) is clearly observed in the intrinsic spectral region from hydrothermally grown $\mathrm{ZnO}$ samples. Emission from both the ground state and excited states of the free exciton is shown in Fig. 4. The ground state emission is shown in both the absence (solid line) and presence (dashed line) of an applied magnetic field. The ground state consists of a $\Gamma_{5}$ allowed exciton $(3.3758 \mathrm{eV})$, and a $\Gamma_{6}$ forbidden exciton $(3.3740 \mathrm{eV})$ which is allowed in the presence of an applied magnetic field. Observation of both the $\Gamma_{5}$ and $\Gamma_{6}$ excitons is characteristic of good quality material. 


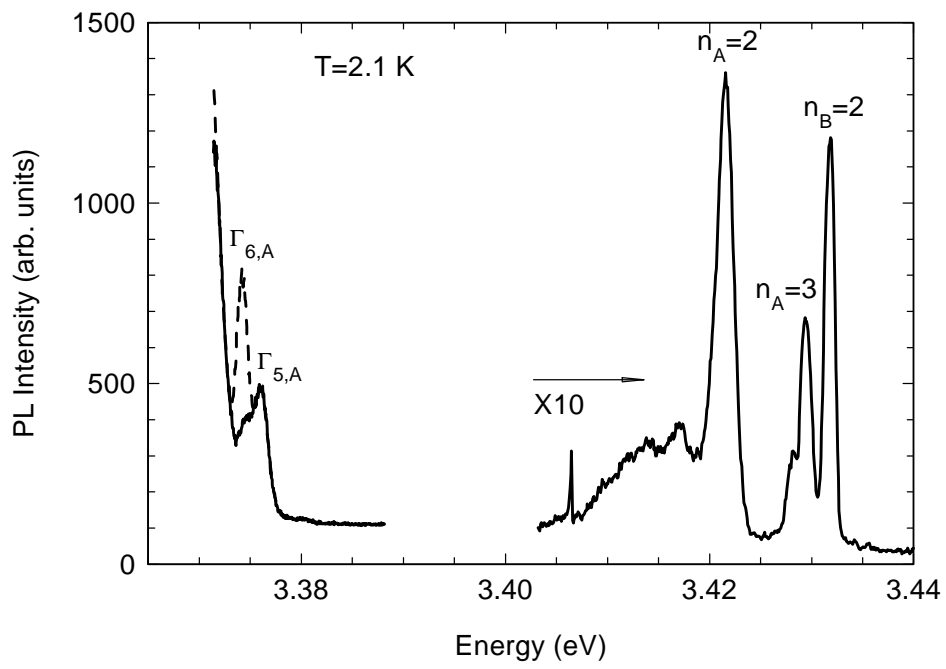

Figure 4. PL Emission of hydrothermal zinc oxide sample.

The observation of excited states of the ground state excitons is even more indicative of high quality material. The $\mathrm{n}=2$ states of the $\Gamma_{5}$ and $\Gamma_{6}$ excitons associated with a valence band are not resolved, and occur at $3.4214 \mathrm{eV}$. The $\mathrm{n}=3$ states of these excitons are resolved and occur at $3.4295 \mathrm{eV}$ for the $\Gamma_{5}$ exciton and at $3.4280 \mathrm{eV}$ for the $\Gamma_{6}$ exciton. The selection rules are relaxed for the excited state transitions. From the emission spectra, the exciton binding energies can be obtained assuming the excited states are hydrogenic. The $n=2$ state of the exciton associated with the B-valence band is observed at $3.4318 \mathrm{eV}$. The ground state B-exciton (not shown) occurs at $3.3885 \mathrm{eV}$. These data demonstrate that high quality $\mathrm{ZnO}$ can be grown by the hydrothermal technique.

The PL spectra in Fig. 5 compare hydrothermal ZnO grown at AFRL Hanscom with vaporphase grown $\mathrm{ZnO}$ provided by Eagle-Picher.

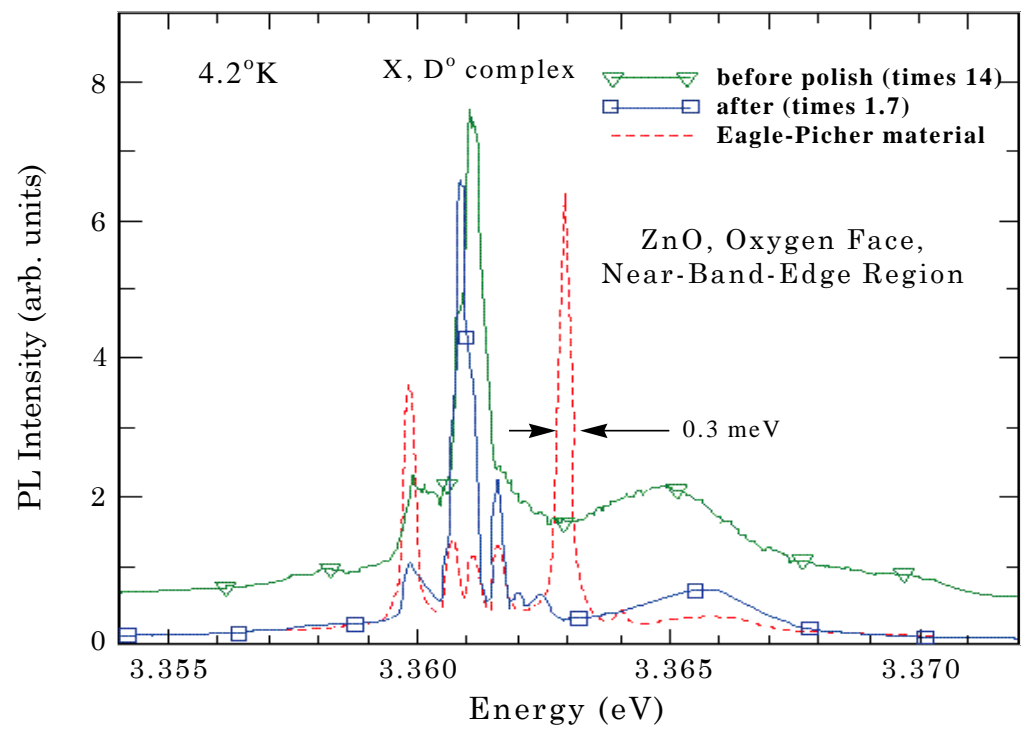

Figure 5. Photoluminescence (at $4.2 \mathrm{~K}$ ) comparing hydrothermal $\mathrm{ZnO}$ and vapor-phase grown $\mathrm{ZnO}$.

Photoluminescence of both Hanscom's hydrothermal and Eagle-Picher's (E-P) vaportransport grown $\mathrm{ZnO}$ crystals (at $4.2 \mathrm{~K}$ ) is most intense in the near-band-edge energy region, as shown in Figure 5. Spectra have been slightly shifted in energy to facilitate direct comparisons. This figure is for the PL from oxygen face. All the sharp transitions are emissions from the 
decay of an exciton bound to a complex of a neutral donor and some unknown impurity or defect (X, $\mathrm{D}^{\circ}$ complex). A comparison of the FWHM and intensity for the two samples with the same surface preparation (E-P polish) but different growth methods shows nearly identical material quality . A comparison of PL spectra for the same Hanscom crystal before and after E-P polish demonstrates the importance of surface preparation. PL from this sample after E-P polish (square markers) is sharper and eight times stronger than before E-P polish (triangle markers). The energy positions of lines this sharp are subject to strain and other point-to-point variations.

The high quality of both Hanscom's hydrothermal and E-P's vapor-transport ZnO crystals is again indicated by the sharp PL (not shown) from the zinc face of the two samples (at $4.2 \mathrm{~K}$ ) which have received E-P's polish. For the zinc face, the comparison of PL spectra from the same Hanscom sample before and after E-P polish is even more striking than from the oxygen face: PL from the hydrothermal sample before the E-P polish was much broader and three orders of magnitude less intense.

\section{CONCLUSIONS:}

High quality, bulk $\mathrm{ZnO}$ was grown hydrothermally. The high quality of the crystals in this study was demostrated by narrow $\mathrm{x}$-ray rocking curves and sharp PL peaks. The crystal color is non-uniform because of its anisotropic crystal growth habit in which the growth rate of each sector depends on orientation. Slices cut from the lighter region are semi-insulating, whereas those from the dark sector are n-type conducting. Anisotropy is also seen in surface quality of polished slices. For slices cut and polished on both sides of the basal plane, the oxygen face yields sharper and more intense room temperature PL peaks, and a narrower x-ray rocking curve. Improved polishing methods result in significantly improved surface quality as measured by the PL and rocking curve widths. When properly polished, hydrothermal $\mathrm{ZnO}$ exhibits optical properties similar to vapor phase grown $\mathrm{ZnO}$. Therefore, proper surface preparation is necessary to evaluate the quality of $\mathrm{ZnO}$ substrates. For epitaxy, e.g. of $\mathrm{GaN}$, special care is required to insure that $\mathrm{ZnO}$ surfaces are of high quality.

\section{ACKNOWLEDGEMENTS}

This work was funded in part by Air Force Office of Scientific Research.

\section{REFERENCES}

(1) D. M. Bagnall, Y. F. Chen, Z. Zhu, T. Yao, M. Y. Shen, and T. Goto, Appl. Phys. Lett. 73 (1998) 1038.

(2) R. R. Monchamp, "Growth of Zinc Oxide Crystals - Interim Engineering Progress Report," Airtron Division of Litton Industries, Morris Plains, New Jersey, ASD project Nr.-7-988, Contract No. AF33(657)-8795, November, 1964.

(3) A. N. Mariano and R. E. Hanneman, J. Appl. Phys. 34 (1963) 384.

(4) D. F. Croxall and R. Ward, J. Cryst. Growth, 22 (1974) 117. 